\title{
Apoptosis of Human Pancreatic Carcinoma PC-2 Cells by an Antisense Oligonucleotide Specific to Point Mutated K-ras
}

\author{
Wang Yongxiang • Gao Liang • Shao Qinshu
}

Received: 19 December 2012 / Accepted: 3 June 2013 / Published online: 5 July 2013

(C) The Author(s) 2013. This article is published with open access at Springerlink.com

\begin{abstract}
The prognosis of pancreatic carcinoma is poor due to the difficulty in early diagnosis, insensitivity to routine therapies and limited understanding of its pathological mechanisms. Gene therapy is now becoming an important strategy for the treatment of pancreatic carcinoma, which includes antisense gene therapy. In this study, we investigated the effect of an antisense oligonucleotide specific to point mutated K-ras on the apoptosis of human pancreatic carcinoma cells in vitro. Human pancreatic carcinoma PC-2 cells were transfected with an antisense oligonucleotide specific to a K-ras point mutation by liposomes. The effect of the antisense oligonucleotide on the apoptosis of PC-2 cells was studied using flow cytometry, TUNEL, and phase contrast microscopy. An apoptotic peak was observed in the experimental group, and most cells were arrested at the G1 phase with few cells at the $\mathrm{S}$ phase. The numbers of apoptotic cells in the experimental group increased as indicated by TUNEL and phase contrast microscopy. An antisense oligonucleotide specific to a K-ras point mutation promotes apoptosis in PC-2 cells in vitro perhaps by inhibition of ras gene expression.
\end{abstract}

Keywords Pancreatic carcinoma $\cdot \mathrm{K}$-ras gene $\cdot$ Antisense oligonucleotide · Target gene

W. Yongxiang $\cdot$ S. Qinshu

Department of General Surgery, Zhejiang Provincial People's

Hospital, Hangzhou 310014, China

G. Liang $(\bowtie)$

Department of Oncology, Zhejiang Provincial People's Hospital, Hangzhou 310014, China

e-mail: yxwang910@yahoo.com.cn

\section{Introduction}

Pancreatic carcinoma is a digestive malignant tumor that is difficult to diagnose early and has a poor prognosis. Its incidence has increased in recent years without significant progress in therapeutic treatment. The general 5 year survival rate is as low as $5-10 \%$, and the improved 5 year survival rate is about 20-40\% after successive whipple operation [1]. Early diagnosis is critical for successful surgical treatment [2].

Significant progress has been made recently in genetic diagnosis and the treatment of pancreatic carcinoma using new biological techniques [3-5]. Antisense gene therapy is now an important strategy of gene therapy $[6,7]$. The AUG start site or 5' cat site are usually selected as target gene sequences for the treatment of pancreatic carcinoma [7-9], but few reports have selected the mute gene as a target. This study investigated the effect of an antisense oligonucleotide specific to point mutated K-ras on the apoptosis of human pancreatic carcinoma cells in vitro.

\section{Methods}

The human pancreatic carcinoma cell line PC-2 was cultured in RPMI 1640 medium supplemented with $10 \%$ fetal bovine serum in a humidified atmosphere with $5 \% \mathrm{CO}_{2}$. Cells were divided into two groups with 16 wells of cells each. For the experimental group, PC-2 cells were transfected with an antisense oligonucleotide (5' CTA CGC CAC GAG CTC CA $3^{\prime}$ ) specific to a K-ras point mutation and then incubated for $24 \mathrm{~h}$. For the control group, PC-2 cells were transfected with a sense oligonucleotide (5'TGG AGC TCG TGG CGT 
AG $3^{\prime}$ ) and then incubated for $24 \mathrm{~h}$. Oligonucleotides were transfected by lipofectamine, and cells were cultured for $24 \mathrm{~h}$ followed by total medium exchange after $8 \mathrm{~h}$.

\section{Flow Cytometric Analysis}

Cells in logarithmic growth were digested, washed, resuspended as single cells and then cultured in a $100 \mathrm{ml}$ culture bottle. Culture medium was exchanged every $48 \mathrm{~h}$, and oligonucleotides were transfected by lipofectamine at $60 \%$ confluence. Culture medium was completely exchanged after $8 \mathrm{~h}$ of culture. Cells were then digested, washed, resuspended as single cells and fixed with $75 \%$ alcohol for $2 \mathrm{~h}$ at $4{ }^{\circ} \mathrm{C}$. The cell cycle, apoptotic peak and percentage were detected by flow cytometry after staining.

\section{TUNEL Detection}

Cells in logarithmic growth were digested, washed, resuspended and then cultured in 24-well culture plates with $600 \mu \mathrm{l}$ medium/well at $3 \times 10^{5}$ cells $/ \mathrm{ml}$. After $24 \mathrm{~h}$, oligonucleotides were transfected by lipofectamine. Culture medium was completely exchanged after $8 \mathrm{~h}$ of culture. Cells were then stained and photographed after $48 \mathrm{~h}$ according to the TUNEL protocol.

\section{Phase Contrast Microscopy}

Cells in logarithmic growth were harvested and cultured in a $100 \mathrm{ml}$ culture bottle. Culture medium was exchanged every $48 \mathrm{~h}$, and oligonucleotides were transfected by lipofectamine at $60 \%$ confluence. Culture medium was completely exchanged after $8 \mathrm{~h}$ of culture. After $48 \mathrm{~h}$, apoptotic bodies were detected and photographed under an inverted phase contrast microscope. According to the number of labeled cells, labeled was designated as $-(0),+(1-5),++(6-10)$, and $+++(>10)$. The number of apoptotic cells was analyzed by SPSS 10.0 statistical software.

\section{Results}

\section{Flow Cytometer Results}

There was an apparent apoptotic peak before the G1 phase of the cell cycle in the experimental group. The apoptotic rate was $31.8 \%$ in the experimental group. There was no apparent apoptotic peak in the control group (Figs. 1 and 2). Most cells in the experimental group were arrested at the G1 phase, and the number of $\mathrm{S}$ phase cells was decreased compared

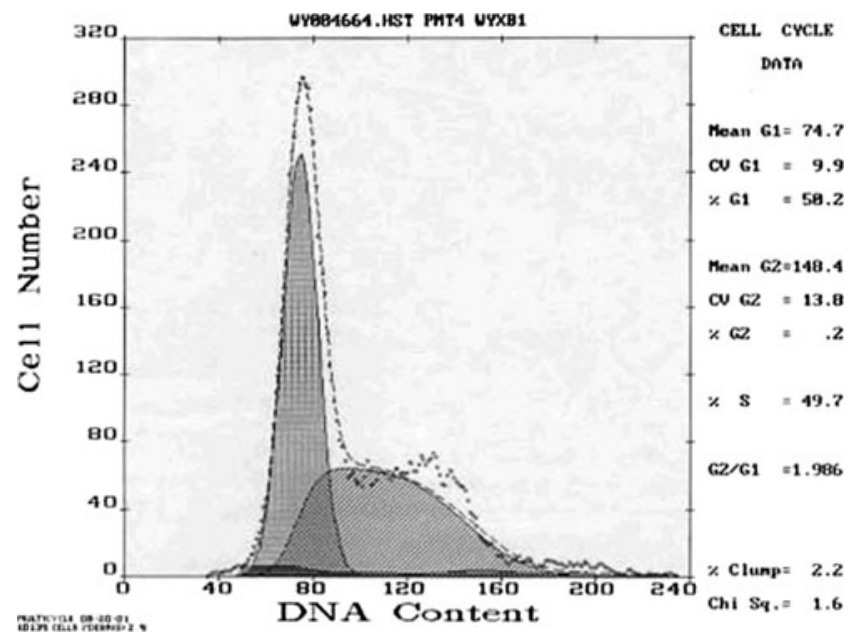

Fig. 1 Cell cycle distribution histogram of the control group (There was no apparent apoptotic peak before G1 phase in the cell cycle)

with that of the control group $(P=0.038)$ (Table 1), indicating an increase in apoptotic cells and a decrease of cell proliferation after transfection with the antisense oligonucleotide.

\section{TUNEL Results}

The characteristics of apoptotic cells were observed under a microscope after TUNEL, in which labeled cells showed brown yellow granules in the nucleus. Five fields of vision were selected randomly for each group under $\times 400$ magnification, and labeled cells were counted and averaged. The number of apoptotic cells in the experimental group increased compared with that of the control group $(P=0.026)$ (Table 2, Fig. 3 and 4).

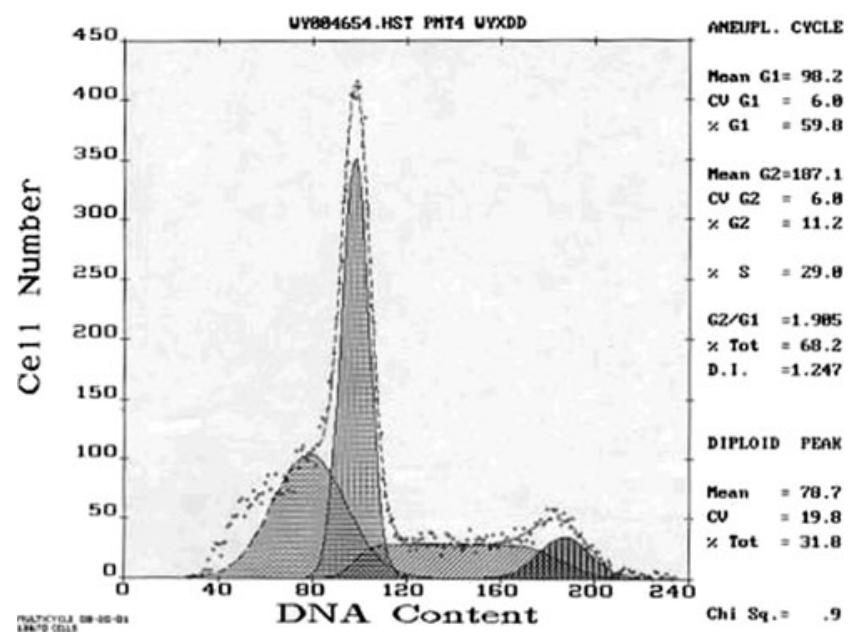

Fig. 2 Cell cycle distribution histogram of the experimental group (There was an apparent apoptotic peak before G1 phase in the cell cycle) 
Table 1 Cell cycle distribution

\begin{tabular}{llll}
\hline & \multicolumn{2}{l}{ Cell cycle distributing } \\
\cline { 2 - 4 } & $\mathrm{G} 1$ & $\mathrm{~S}$ & $\mathrm{G} 2$ \\
\hline Experimental group & $59.8 \%$ & $29.0 \%$ & $11.2 \%$ \\
Control group & $50.2 \%$ & $49.7 \%$ & $0.1 \%$ \\
P value & $P=0.29$ & $P=0.038$ & $P=0.029$ \\
\hline
\end{tabular}

\section{Phase Contrast Microscopy Results}

Apoptotic bodies were observed under an inverted phase contrast microscope after $48 \mathrm{~h}$ of culture. The number of cells with apoptotic bodies in the experimental group increased compared with that of the control group. The shape of apoptotic cells became atrophic and rounded, and some little froth or ball-shaped apoptotic bodies were observed on the apoptotic cell surface. Some cells detached from the culture vessel and were suspended in the medium (Figs. 5 and 6).

\section{Discussion}

Excessive cell proliferation and abnormal differentiation are major reasons of tumor occurrence, and deregulation of cell death is a major factor for the occurrence of carcinoma. Cell proliferation and cell death are accurately balanced under a normal condition, and carcinoma occurs once this balance is disrupted.

Cell death is generally classified into two types, necrosis and apoptosis. Cell apoptosis is a form of programmed cell death and occurs when cells receive certain signals or stimulation. Moreover, cell apoptosis is a method of clearing injured or nonfunctioning cells from the body without changing the function of the tissue. Cell apoptosis plays an important regulatory role under normal and pathological conditions.

Previous studies have mainly focused on the excessive proliferation of carcinoma cells as the mechanism of carcinoma occurrence. It has been recently found that cell apoptosis participates in the occurrence of carcinoma at several

Table 2 Comparison of cell apoptosis between the two groups

\begin{tabular}{lllllllll}
\hline & \multicolumn{3}{l}{ Apoptosis cells } & Expression rate & P value \\
\cline { 2 - 5 } & - & + & ++ & +++ & & \\
\hline Experimental group & 2 & 3 & 4 & 1 & $80 \%$ & $P=0.026$ \\
Control group & 8 & 2 & 0 & 0 & $20 \%$ & \\
\hline
\end{tabular}

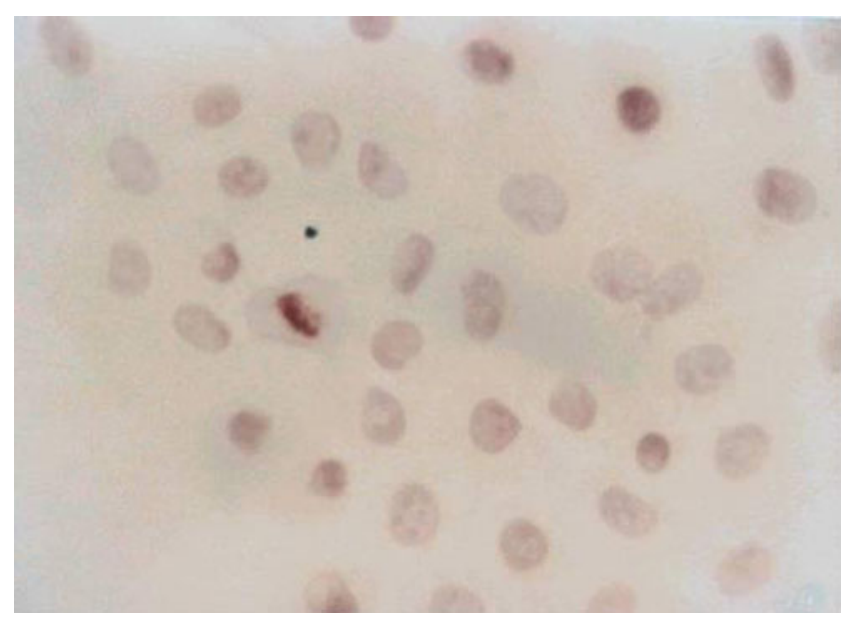

Fig. 3 Apoptotic cells in the control group (TUNEL, $\times 400$ )

phases. Excessive cell proliferation may trigger excessive cell cloning whereas apoptosis can restrain it.

It has been reported that cell apoptosis is blocked in the early stage of carcinoma occurrence [10], indicating that it may be possible to treat carcinoma by inducing cell apoptosis. Under normal condition, cell apoptosis can clear DNAinjured and potentially malignant cells. Disruption of apoptotic function can promote the development of carcinoma [11]. Inducing apoptosis may reduce DNA-injured and potentially malignant cells and thus prevent or inhibit carcinoma growth. In contrast, inhibition of apoptosis may facilitate pre-carcinoma cells. Arya et al. reported that stimulating cell apoptosis can be an anti-carcinoma strategy [12]. Inducing apoptosis in carcinoma cells appears to be more physiological than killing carcinoma cells directly because it avoids the side effects of chemotherapeutic drugs. The dynamic balance between cell proliferation and cell apoptosis has a major effect on the initiation of pre-carcinoma and carcinoma cells, and cell apoptosis has an important function in the nontransmissibility of carcinogenic course.

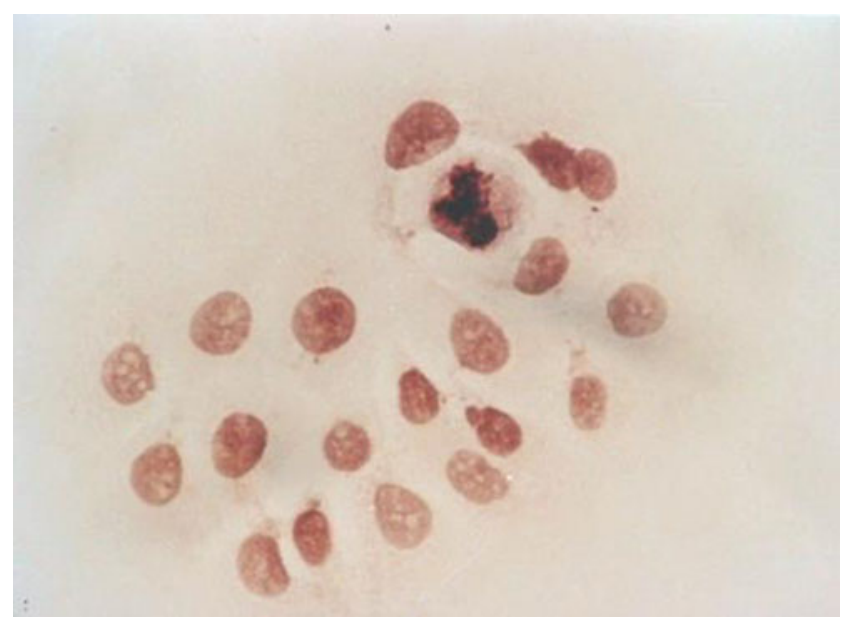

Fig. 4 Apoptotic cells in the experimental group (TUNEL, $\times 400)$ 


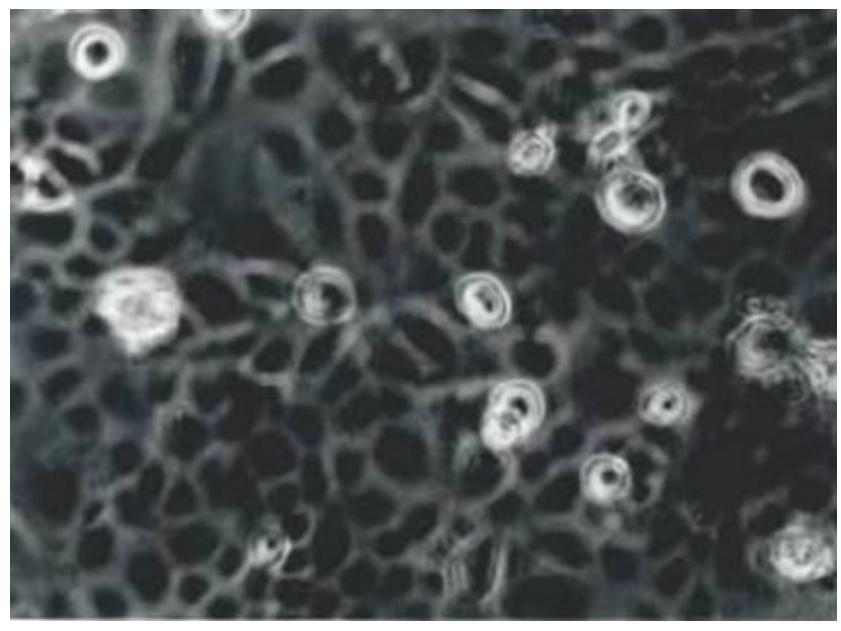

Fig. 5 Apoptotic bodies in the experimental group (Phase contrast microscopy, $\times 100$ )

Cell apoptosis is regulated by two mechanisms, namely programmed gene regulation such as the replacement of old cells with new cells under a physiological condition, and non-gene regulation in which injury factors, such as TGF- $\beta$ and TNF, damage DNA directly or indirectly and thereby disturb cell proliferation and induce cell apoptosis.

Most studies of cell apoptosis have focused on the effect of apoptotic genes on apoptosis. Few studies have focused on the effect of the cancer gene on cell apoptosis. It has been reported that cell apoptosis is related to the expression level of the cancer gene. A potential approach to restrict the expression of the cancer gene may be via inducing cell apoptosis [13]. Many reports have shown that the ras gene can increase cell proliferation [14, 15], but few studies show the effect of the ras gene on cell apoptosis. We have previously reported an

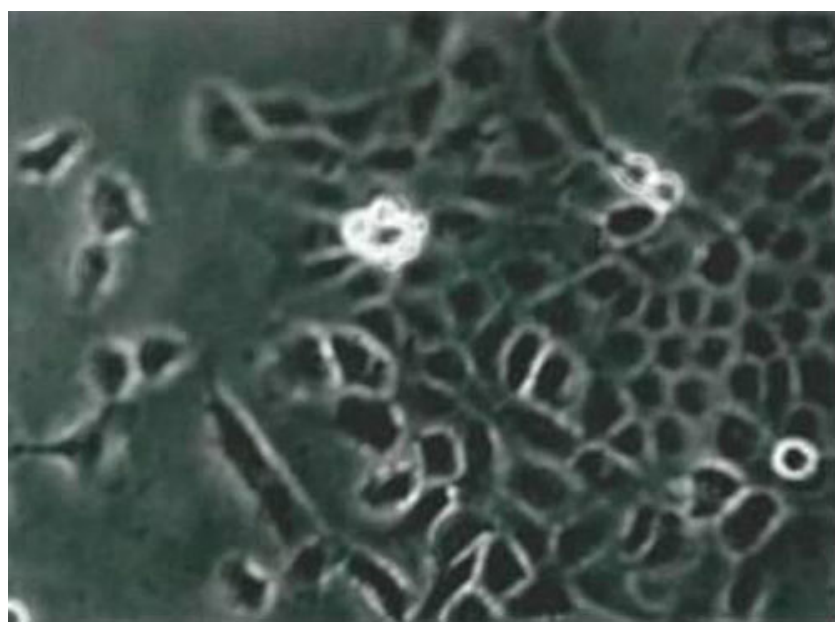

Fig. 6 Apoptotic bodies in the control group (phase contrast microscopy, $\times 100$ ) antisense oligonucleotide specific to a K-ras point mutation, which can inhibit the expression of the ras gene [16]. Our study showed that the experimental group had significantly increased apoptosis.

It has been reported that the ras protein not only regulates cell proliferation and differentiation, but also promotes carcinoma occurrence by inhibiting cell apoptosis ${ }^{17}$. Kinoshita et al. reported that apoptosis of hematogenous cells is inhibited after transfection of the of k-ras gene in vitro. Further study showed that this effect is caused by an increase in bcl-2 gene expression [15]. Ward et al. reported that the decrease in cell apoptosis is closely related to activation of the k-ras gene $[17,18]$. The first mechanism may be early genetic changes that desensitize cells to apoptotic stimuli, and then silenced gene expression is easily transferred to the next generation [19]. The second mechanism may involve activation of the ras protein, which may inhibit apoptosis directly or indirectly. Mizukami et al. reported that farnesylamine can inhibit the ras protein on the membrane and the ras signaling pathway to promote cell apoptosis [20]. It has been shown that the ras protein plays an important role in the regulation of cell apoptosis.

The ras gene plays an important role in the multiple steps of carcinoma development. The ras gene regulates the expression of many other genes that have important functions in regulating the mutual effect between carcinoma and the host. Fenton et al. reported that the fas mRNA level in cells transfected with the ras gene decreases significantly, indicating that the ras gene can restrict the expression of fas via several mechanisms [21]. Fushida et al. reported that human pancreatic carcinoma cells transfected with the ras gene lose fas receptor function at various levels of the fas signal transduction pathway [22]. Gulbins et al. reported that apoptosis induced by the fas gene is mediated by the ras signaling pathway, and activation of the ras gene is the key step in this apoptotic pathway because apoptosis induced by the fas gene can be inhibited by an antibody that inhibits or counteracts ras gene mutation [23]. Moreover, blocking the fas gene can stimulate the sphingomyelin signaling pathway to produce acyl sphingosine that can activate the ras gene and induce apoptosis. It has been shown that ras and fas genes are inter-regulated to induce cell apoptosis. However, the ras gene can promote tumor occurrence by inhibiting tumor cell apoptosis by several mechanisms.

Our study indicates that an antisense oligonucleotide specific to a K-ras point mutation can promote apoptosis of the human pancreatic carcinoma cell line PC-2 in vitro, which is likely mediated by inhibition of ras gene expression. 
Open Access This article is distributed under the terms of the Creative Commons Attribution License which permits any use, distribution, and reproduction in any medium, provided the original author(s) and the source are credited.

\section{References}

1. Zongzheng J, Yongxiang W, Xi C, Tao W (2003) Peripancreatic artery ligation and artery infusion chemotherapy for advanced pancreatic carcinoma. Chin Med J 116:89-92

2. Luttges J, Hahn S, Kloppel G (2004) Where and when does pancreatic carcinoma start? Med Klin (Munich) 99:191-195

3. Shuanzeng W, Tonghua L, Hongrui L, Jie G (2003) Unique GGT $\rightarrow$ GTT mutation at K-ras codon 12 in six human pancreatic cancer cell lines from Chinese patients. Chin Med J 116:1585-1587

4. Luttges J, Stigge C, Pacena M, Kloppel G (2004) Rare ductal adenocarcinoma of the pancreas in patients younger than age 40 years. Cancer 100:173-182

5. Wei S, Liang Z, Gao J, Wu S, Liu H, Liu T (2005) Patterns of K-ras codon 12 and 13 mutations found in pancreatic adenocarcinoma of 30 Chinese patients by microdissection, PCR and direct sequencing. J Gastroenterol Hepatol 20:67-72

6. Matsubayashi $\mathrm{H}$, Watanabe H, Ajioka Y, Nishikura K, Yamano M, Seki T et al (2000) Different amounts of K-ras mutant epithelial cells in pancreatic carcinoma and mass-forming pancreatitis. Pancreas 21:77-85

7. Kita K, Saito S, Morioka CY, Watanabe A (1999) Growth inhibition on human pancreatic cancer cell lines by anti-sense oligonucleotides specific to mutated K-ras genes. Int J Cancer 80:553-558

8. Higgins KA, Peres JR, Coleman TA, Dorshkind K, McComas WA, Sarmiento UM et al (1993) Anti-sense inhibition of the p65 submit of NF-k B block tumorigenecity and causes tumor regression. Proc Nat Acad Sci 90:9901-9905

9. Tonghua L, Zhiyong W, Lei Z (1997) The inhibitary effect of modified Antisense oligonucleotide on the growth of pancreatic carcinoma cell and the expression of target gene. Chin J Patho 26:147151

10. Hoffmann B, Lieberman DA (1994) Molecular regulation of apoptosis: differentiation/growth arrest primary response genes, protooncogenes, and tumor suppressor genes as positive and negative modulation. Oncogene 9:1807-1812
11. Jaattela M (1999) Escaping cell death: survival proteins in cancer. Exp Cell Res 248:30-43

12. Arya J, Finlayson CA, Shames BD et al (2000) Stimulated apoptosis as an antineoplastic strategy. Surgery 127:366-369

13. Humenil D, Neel H, Lacout C et al (1994) Infection with a Kirstenretrovirus can induce a multiplicity of tumorigenic phenotypes in the interleukin-3-dependent FDC-P1 cells. Exp Hematol 22:178185

14. Kinoshita T, Yokota T, Aria KI et al (1995) Regulation of bcl-2 expression by oncogene ras protein in hematopoietic cells. Oncogene 10:2207-2212

15. Arends MJ, McGregor AH, Wyllie AH (1994) Apoptosis is inversely related to necrosis and determines net growth in tumors bearing constitutively expressed myc, ras, and HPVoncogenes. Am J Pathol 144:1045-1052

16. Yong-xiang W, Liang G, Zong-zheng J (2007) Inhibitary effects of antisense oligonucleotide specific to K-ras point mutation on the target gene expression in human pancreatic carcinoma cells. Chin Med J 120:1448-1450

17. Ward RL, Todd AV, Santiago F et al (1997) Activation of the K-ras in colorectal neoplasms is associated with decreased apoptosis. Cancer 70:1106-1113

18. Peli J, Schroter M, Rudaz C et al (1999) Oncogenic Ras inhibits Fas ligand-mediated apoptosis by downregulating the expression of Fas. EMBO J 18:1824-1831

19. Potten CS, Li YQ, O'Connor PL et al (1992) A possible explanation for the differential cancer incidence in the intestine, based on distribution of the cytotoxic effects of carcinogens in the murine large bowel. Carcinogenesis 3:2305-2312

20. Mizukami Y, Ura H, Obara T et al (2001) Requirement of cjun N-terminal kinase for apoptotic cell death induced by farnesyltransferase inhibitor, farnesylamine, in human pancreatic cancer cells. Biochem Biophys Res Commun 288(1):198204

21. Fenton RG, Hixon JA, Wright PW et al (1998) Inhibition of Fas (CD95) expression and fas-mediated apoptosis by oncogenic ras. Cancer Res 58:3391-3400

22. Fushida S, Nishimura GI, Shimizu K et al (2001) Human pancreatic cancer cells disable function of fas receptors at several levels in fas signal transduction pathway. Int J Oncol 18:311316

23. Gulbins E, Bissonnette R, Mahboubi A et al (1995) Fas induced apoptosis is mediated via a cermide-initiated RAS signaling pathway. Immunity 2:341-351 